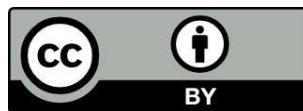

\title{
DISCÓRDIAS RELIGIOSAS NA IMPRENSA CURITIBANA (1930)
}

\author{
Religious Disagreements in the "Curitibana” Press (1930)
}

Edilson Soares de Souza

Doutor em História pela UFPR; Professor na Faculdade Teológica Batista do Paraná E-mail: edilsonssouza@uol.com.br

RESUMO: No início de 1930 o jornal A República publicou uma série de Cartas Abertas, assinadas por Antenor Manso Cordeiro, e endereçada ao reverendo Agenor Mafra, pastor da denominação presbiteriana no Brasil. Tratava-se de outro momento nos confrontos entre Católicos e Protestantes, no contexto de um Estado não confessional. As sete cartas publicadas no jornal ajudam a compreender os embates religiosos entre os intelectuais cristãos, como também as estratégias utilizadas para defender o pensamento religioso de confissão cristã nas primeiras décadas do século $\mathrm{XX}$, a partir da impressa em Curitiba, no Estado do Paraná.

Palavras-chave: Confrontos religiosos; Catolicismo romano; Protestantismo.

ABSTRACT: In the beginning of 1930 the newspaper A República published a series of Open Letters, signed by Antenor Manso Cordeiro, and addressed to Reverend Agenor Mafra, pastor of the Presbyterian denomination in Brazil. It was another moment in the confrontation between Catholics and Protestants, in the context of a nondenominational State. The seven letters published in the newspaper helped to understand the religious conflicts between Christian intellectuals, as well as strategies used to defend the religious thought of Christian confession in the first decades of the twentieth century, from the press in Curitiba, State of Paraná.

Key words: Religious confrontations; Roman Catholicism; Protestantism. 


\section{Introdução}

Para Hans Küng "não haverá paz entre as nações sem paz entre as religiões. Não haverá paz entre as religiões sem diálogo entre as religiões. Não haverá diálogo entre as religiões sem padrões éticos globais. Na haverá sobrevivência na Terra com paz e justiça sem que surja um novo paradigma nas relações internacionais, baseado em padrões éticos”, (KÜNG, 2005, p. 09). No que pese as expectativas do teólogo cristão sobre a paz entre as nações, intermediada pelos diálogos entre as religiões, percebe-se que a trajetória das religiões foi marcada por discórdias com outras confissões, como também por discórdias internas. Foi assim com a religião cristã no contexto brasileiro, marcadamente entre o final do século XIX e parte do século XX.

O presente artigo, que é o resultado de parte dos estudos desenvolvidos para a defesa da tese de doutorado em História na UFPR, analisa um conjunto de Cartas publicadas no jornal A República (janeiro de 1930), assinadas por Antenor Manso Cordeiro. São 07 (sete) cartas com conteúdo polêmico, endereçadas ao reverendo presbiteriano Agenor Mafra, que estabeleceu alguns confrontos religiosos com o Bispo de Jacarezinho, Dom Fernando Taddei. Embora as cartas fossem dirigidas ao reverendo Mafra, elas se tornaram públicas, quando publicadas num jornal sem intenções confessionais explícitas.

As sete cartas de Antenor Manso Cordeiro devem ser compreendidas a partir das discórdias entre escritores cristãos, representantes do catolicismo romano e do protestantismo de viés presbiteriano. Deve-se destacar que outros textos foram produzidos pelos dois autores, permitindo um estudo de caso sobre os confrontos religiosos no contexto social brasileiro, após a Proclamação da República. Cabe ressaltar que as discórdias religiosas que chegaram à imprensa curitibana originaram-se da publicação da Carta Pastoral elaborada pelo Bispo de Jacarezinho, no Estado do Paraná, intitulada A Propaganda Protestante e os deveres dos Catholicos, quando Dom Fernando Taddei advertiu sobre os perigos associados ao crescimento do protestantismo no Brasil. Conquanto possam ser percebidos outros confrontos religiosos naquele período, o presente artigo ocupa-se da análise de parte do conteúdo das sete cartas de Manso Cordeiro. Para Agenor Mafra, autor de O Papismo perante a Biblia: a Historia e os Factos, Antenor Manso Cordeiro era o pseudônimo do Bispo de Jacarezinho, Dom Fernando Taddei. No estudo a seguir objetiva-se compreender parte das discórdias entre 
dois escritores do cristianismo. Os dois intelectuais defenderam as suas convicções religiosas, inclusive, utilizando-se a impressa para expor os seus pensamentos.

\section{Desenvolvimento}

Sobre as Cartas de Antenor Manso Cordeiro, pode-se dizer que a primeira das sete cartas foi publicada em 18 de janeiro de 1930, intitulada "O primado de S. Pedro e dos Papas, seus successores. Cartas abertas ao sr. Agenor Mafra. Carta Primeira", (A República, Edição de 18 de janeiro de 1930, p. 02). É importante frisar que, enquanto a primeira carta foi inserida na edição do dia 18 de janeiro, a segunda carta circulou um dia antes, sendo publicada em 17 de janeiro de 1930. Assim, os leitores foram apresentados ao texto da segunda carta, para depois terem contato com o conteúdo da primeira carta. Quanto ao título que consta da primeira carta, ele foi utilizado como referência em toda a série, constando das demais cartas que circularam entre 17 e 25 de janeiro de 1930.

Em sua primeira carta, Antenor Manso Cordeiro indicou a razão da produção dos textos, dizendo: "Sr. Ministro. O fim desta carta, e das outras que vão seguir, é refutar as principaes accusações e asserções gratuitas, contidas no seu folheto contra a Pastoral do exmo. sr. bispo de Jacarezinho", (A República, Edição de 18 de janeiro de 1930, p. 02). E acrescentou em suas palavras introdutórias que "comquanto não tenha eu visto nunca as suas credenciaes, pela simples razão que taes credenciaes não existem, não deixarei, todavia, de lhe dar, na falta de outro título, o de ministro, que o sr. usurpa”, (A República, Edição de 18 de janeiro de 1930, p. 02). Percebe-se que parte do conteúdo das discórdias tem a ver com o questionamento sobre a competência do adversário, que se coloca em posição de polemista, refutando as afirmações do opositor.

Na segunda carta, que circulou no dia 17 de janeiro, o autor partiu objetivamente para o confronto, fazendo perguntas e apresentando respostas.

Escreveu em seu segundo texto Manso Cordeiro:

Sr. Ministro. Leio, no seu folheto: 'S. Pedro nunca foi papa, e o papa nunca foi successor de S. Pedro, e vamos proval-o'. Devéras? senhor ministro. Então, na sua opinião, tantas gerações, tantos povos, tantos genios immortaes, que floresceram na terra, durante vinte seculos - e ainda florescem - e que professaram - e ainda professam - que S. Pedro foi Papa, e que os Papas são os legítimos successores de S. Pedro, foram - ou são - uma collecção de imbecis? (A República, Edição de 17 de janeiro de 1930, p. 12). 
As perguntas com as respectivas respostas se sucedem, caracterizadas pela motivação de um confronto religioso em defesa das convicções e das crenças religiosas. Mas as expressões e os termos utilizados na série de cartas indicam também a motivação e a uma clara intenção no sentido de se desqualificar o oponente, num esforço de revelar e comprovar uma verdade absoluta, negada às denominações cristãs acatólicas, compostas pelas múltiplas igrejas protestantes já instaladas no Brasil, também nomeadas de evangélicas.

Dando continuidade ao seu projeto de discórdias religiosas, Antenor Manso Cordeiro viu publicada a sua terceira carta, que circulou no jornal no dia 21 de janeiro daquele ano, apresentando novos argumentos polêmicos. Manso Cordeiro, então, introduziu o texto da carta, dizendo: "volvo novamente á 'interpretação da passagem', e continu'o a citar o seu folheto: 'A interpretação legitima e cabivel da celebre passagem de S. Matheus, acima citada, é que a pedra fundamental da Igreja era, e é ainda, o proprio Christo, e não S. Pedro", (A República, Edição de 21 de janeiro de 1930, p. 10). A discussão apresentada na carta foi em torno da interpretação sobre o papado, já que Pedro foi considerado o primeiro papa pelo catolicismo romano, o que os autores protestantes recorrentemente questionavam e combatiam, indicando outra interpretação bíblica. Sobre tais interpretações ligadas a figura de Pedro, afirmou Manso Cordeiro que, "essa interpretação não teve o seu nascimento com a reforma protestante do seculo XVI, mas é tão antiga como a Igreja, e tão vetusta como o Evangelho. S. Agostinho, S. João Chrysostomo, Santo Ambrosio, São Jeronymo, Santo Hilário, que foram padres, entenderam-n'a assim"”, (A República, Edição de 21 de janeiro de 1930, p. 10). É interessante observar que a figura do papa estava sendo questionada pelos protestantes, precisando ser defendida firmemente pelos polemistas do catolicismo. Provavelmente, naquele período de adaptações sócio-religiosas, no contexto de um Estado não confessional, reafirmar um dos principais dogmas do catolicismo fosse fundamental para o posicionamento dos católicos diante do avanço dos protestantes no Brasil.

No meio da série de cartas sobre as discórdias com os protestantes, o autor que defendia o catolicismo vai escrever a sua quarta carta, datada de 22 de janeiro, tendo como uma de suas características a extensão do texto, no que pese o mesmo estilo literário. Outra forte característica desta série, cujo clímax foi dado por esta quarta carta, foi conservada: buscar provocar, desqualificar e de alguma forma intimidar o oponente 
protestante. Para o autor, das duas uma: "ou o sr. ministro sabe o que escreve, e, nesse caso, está a mentir - porque affirma o que não é exacto - ou não sabe o que escreve - o que é mais provavel, para não dizer certo - e, nesse caso, é um ignorante”, (A República, Edição de 22 de janeiro de 1930, p. 12). Parece, na opinião do missivista, que o reverendo presbiteriano agiu com falsidade em seus argumentos, ou indicou certa ignorância quanto a construção da defesa de suas convicções religiosas.

As últimas três cartas (da quinta a sétima) foram publicadas entre os dias 23 e 25 daquele janeiro de 1930. Com elas, Antenor Manso Cordeiro concluiu o seu projeto de empreender as discórdias religiosas a partir de um jornal não confessional, que circulou entre os leitores curitibanos. Algo que chama a atenção quando se analisa a última carta desta série é a inserção de um anexo, que segue ao texto principal sobre as polêmicas de Manso Cordeiro. Depara-se neste anexo com uma referência à Carta Pastoral de Dom Fernando Taddei, Bispo em Jacarezinho, dando a seguinte informação: "ANNEXO. A grande e autorisada revista 'LA Civiltá Catholica', no seu fasciculo numero 1906, de 15 de Novembro de 1929, refere-se, nestes termos, á Pastoral do Exmo. e Rvmo. Sr. Bispo de Jacarézinho: Mons. FERNANDO TADDEI, Bispo de Jacarézinho. - A propaganda protestante e os deveres dos catholicos, Pastoral. Curityba. Tip. 'A Cruzada', 1929, in-8, pp. 108”, (A República, Edição de 25 de janeiro de 1930, p. 12).

A tradução do texto publicado sobre a Pastoral do Bispo de Jacarezinho apresentava o seguinte teor, reforçando a intensidade das discórdias religiosas entre o escritor do catolicismo e o seu oponente, o protestante Agenor Mafra:

TRADUCÇÃO. Julgamos dever abrir uma excepção á norma geral, annunciando esta importantissima Carta Pastoral, que ventila um dos mais graves e urgentes problemas dos tempos actuais especialmente na America latina, onde a propaganda protestante está emprehendendo herculeos esforços para inflitrar-se nos paises catholicos e alli supplantar a antiga fé. Não podia ser mais opportuna a palavra eloquente e paterna de Dom Taddei. Trata com profundeza o problema da invasão protestante, em linguagem clara e popular, mas tamanha solidez e perspicuidade, que deixa a mais salutar impressão em todos os que lêrem a Pastoral, com ractidão (sic) de coração e com espirito avido e luz e de verdade, (A República, Edição de 25 de janeiro de 1930, p. 12).

Com este anexo, os sete discursos produzidos por Antenor Manso Cordeiro, e publicados no jornal A República, ficam associados ao discurso elaborado pelo Bispo de Jacarezinho, pois no final da série em defesa do primado de Pedro e dos papas, tidos 
como os seus sucessores, fez-se referência ao documento publicado pela diocese daquela cidade no Estado do Paraná, de autoria de Dom Fernando. De alguma forma, o tema sobre os problemas religiosos na América Latina volta à discussão, mas desta vez pelo viés do pensamento católico, já que "a propaganda protestante está emprehendendo herculeos esforços para inflitrar-se nos paises catholicos e alli supplantar a antiga fé", (A República, Edição de 25 de janeiro de 1930, p. 12).

Cabe lembrar que alguns autores discutiram o tema sobre as questões religiosas que envolviam as sociedades no contexto de América Latina, sobretudo, com relação ao Brasil. Tais discussões tornaram-se públicas a partir da elaboração e publicação de alguns folhetos polemistas e livros sobre discórdias religiosas, que enfatizavam o pensamento de determinada denominação do cristianismo, em detrimento de outras, combatidas sistematicamente. As discórdias publicadas no jornal A República, e analisadas neste artigo, fazem parte deste contexto de discussão e apropriação das verdades religiosas, numa sociedade em processo de ajustes e adaptações, após a Proclamação da República.

Retomando a discussão sobre as sete cartas de Manso Cordeiro, pode-se propor uma abordagem com relação ao conteúdo das mesmas, visando uma compreensão mais objetiva das discórdias religiosas ali inseridas. No presente artigo, aponta-se tão somente para um caminho percorrido com relação à análise do conjunto já indicado das fontes indicadas. Nos estudos empreendidos para o doutoramento em história (UFRP), tanto as fontes quanto a abordagem mereceram uma análise mais demorada, revelando outros elementos sobre os confrontos religiosos entre escritores católicos e protestantes, entre o final do século XIX e parte do século XX.

Assim, podem ser percebidas três formas de polêmicas: a) Polêmicas Provocatórias, chamadas assim em função dos confrontos religiosos, que visavam provocar o oponente, tendo a intenção de desqualificá-lo, sobretudo, com relação às suas credenciais para empreender discussões teológicas, doutrinárias e eclesiásticas; b) Polêmicas Hermenêuticas, nomeadas desta forma por remeterem aos confrontos que objetivavam defender as verdades proclamadas pelo catolicismo, como também pelas igrejas ou denominações do protestantismo, enquanto se questionava a interpretação dos autores oponentes; e c) Polêmicas Comprobatórias, que receberam tal classificação em virtude de apontarem para as discórdias religiosas, que objetivavam alcançar, 
comprovar e defender vigorosamente as verdades do cristianismo, utilizando-se, algumas vezes, de termos filosóficos e acadêmicos, buscando comprovar a veracidade de um pensamento ou de uma crença, recorrentemente, em oposição à falsidade do pensamento ou da crença do rival.

Um exemplo de Polêmicas Provocatórias, no contexto das cartas de Antenor Manso Cordeiro, pode ser encontrado na seguinte afirmação:

O PRIMADO DE S. PEDRO E DOS PAPAS, SEUS SUCCESSORES. Cartas abertas ao sr. Agenor Mafra. Carta Primeira. Sr. Ministro. O fim desta carta, e das outras que vão seguir, é refutar as principaes accusações e asserções gratuitas, contidas no seu folheto contra a Pastoral do exmo. sr. bispo de Jacarezinho. Comquanto não tenha eu visto nunca as suas credenciaes, pela simples razão que taes credenciaes não existem, não deixarei, todavia, de lhe dar, na falta de outro título, o de ministro, que o sr. usurpa. Não posso, comtudo, admittir que se arvóre em 'pregador evangelico', porquanto São Paulo expressamente declara que ninguém póde pregar o Evangelho, sem ser enviado por Deus. Isto é, sem ter missão official, que o sr. nunca recebeu. Assentados estes preliminares, prosigamos, (A República, Edição de 18 de janeiro de 1930, p. 02).

A provocação do autor católico junto ao escritor protestante concretiza-se no questionamento sobre as devidas qualificações deste último, que se apresentou como um dos defensores do protestantismo no Brasil. Para Manso Cordeiro, que cita uma produção textual de Agenor Mafra, refutando os argumentos do Bispo de Jacarezinho, o seu oponente não apresentava as devidas qualificações para confrontá-lo, sobretudo, por não apresentar as "credenciais" esperadas pelo seu interlocutor. Na visão do autor, o destinatário de suas cartas públicas não estava devidamente preparado para empreender um confronto religioso com Dom Fernando Taddei. Em sua opinião, Agenor Mafra estava menos qualificado para empreender qualquer outro tipo de debate religioso. Tais polêmicas, em determinados momentos, parecem ser mais pessoais do que discórdias em torno de temas pertinentes ao cristianismo.

Em outro momento das discórdias inseridas nas cartas de Manso Cordeiro, percebe-se que a discussão parece avançar em torno dos assuntos que envolvem o catolicismo e o protestantismo entre os brasileiros. No entanto, numa análise mais detalhada, nota-se que o principal objetivo foi atingir o opositor, num esforço de neutralizá-lo. Na visão de Manso Cordeiro, o reverendo Agenor Mafra apresentava-se como um propagandista de ideias heréticas, revelando-se ainda mais sutil ao proclamar os ensinamentos do protestantismo que confrontava o catolicismo, numa sociedade que 
se pensava católica, embora os questionamentos do próprio clero sobre tal condição religiosa.

Assim, em outra parte do texto, ainda sem entrar nas questões pertinentes aos aspectos das práticas religiosas cristãs, Manso Cordeiro introduziu a metáfora de uma residência, ocupada por um invasor.

Disse ele:

sobrevem o chefe, isto é, o pae, e, agarrando o atrevido pelas orelhas, ou pelas costas, põe-no, sem mais formalidades, no olho da rua. Ora, pergunto eu, acaso poderá o intruso e atrevido queixar-se dos maus tratos recebidos, e accusar o dono da casa de lhe ter faltado com a delicadeza? A mim pareceme, pelo contrario, que deveria dar graças a Deus por lhe ter sahido barato o negocio, pois não resta duvida que poderia ter sido muito peior (sic). Consulte v. s. o seu bom senso, se é que o tem, e verá que as suas lamurias não passam de ingenuidades, (A República, Edição de 18 de janeiro de 1930, p. 02).

Em sua opinião, a sociedade brasileira podia ser comparada a uma casa que foi invadida. Os donos são os católicos romanos, presentes entre os brasileiros desde o período de colonização, passando pela monarquia, até aquelas primeiras décadas da República. Os inconvenientes invasores, que merecem ser expulsos do ambiente, são os protestantes, chegados definitivamente aos portos na primeira parte do século XIX, beneficiados que foram pelos acordos entre o Brasil e determinados países da Europa. Os portos que se abriram aos amigos do Brasil foram os mesmos que receberam os protestantes. Inicialmente, eles se reuniram em suas colônias, conservando as suas práticas culturais e religiosas, para depois expandirem-se por todo o território nacional, compartilhando hábitos, cultura e expressões religiosas. Em 1930 o Brasil não se constituía mais num país católico romano, o que ocorreu até 1889. No final do século XIX as instituições oficiais e jurídicas asseguravam às religiões a liberdade de culto e de propaganda de suas ideias religiosas.

O segundo exemplo tem a ver com as Polêmicas Hermenêuticas, lembrando que tais discórdias objetivavam a defesa interpretativa de determinadas passagens do texto sagrado do cristianismo, neste caso, a Bíblia Sagrada. As discórdias em torno da correta interpretação da Bíblia levaram os autores a estabelecerem discussões sobre determinadas passagens textuais, enfatizando o significado das mesmas. Destaca-se a questão hermenêutica quando se trata do texto de Mateus 16.17-19, tendo como uma 
das figuras da passagem a pessoa de Pedro. As discórdias religiosas inseridas na imprensa curitibana daquela década (1930) sustentavam-se a partir do título de cada uma das sete cartas, ou do título da série, chamada $O$ primado de $S$. Pedro e dos papas, seus successores. O título já indicava a disposição de Antenor Manso Cordeiro, no sentido de defender firmemente a sua posição com relação à figura do papa.

Assim, ele apresentou a sua interpretação do texto sagrado cristão:

vejamos qual o verdadeiro sentido das palavras dirigidas por Nosso Senhor a S. Pedro, quando lhe disse: 'Tu és Pedro, e sobre esta pedra edificarei a minha igreja'. Os catholicos de todos os tempos e lugares, sabem perfeitamente que, por sua essencia e natureza, a Pedra fundamental do majestoso edifício da Igreja é o proprio Filho de Deus, Nosso Senhor Jesus Christo. Sustentam, porém, e com toda a razão, que ao dizer o divino Mestre a S. Pedro: 'Tu és Pedro, e sobre esta pedra edificarei a minha Igreja', prometteu constituil-o, mais tarde, pedra fundamental da sua Igreja, tornando-o participante da divina firmeza e solidez, que lhe é própria. Não querendo, entretanto, os protestantes reconhecer, de forma alguma, a autoridade dos Papas, e nem, por conseguinte, a do primeiro Papa, que foi S. Pedro, e não sabendo, por outro lado, como rejeitar as palavras formaes de Nosso Senhor, excogitaram mil subterfugios, dos quaes o principal consiste em affirmar, como sr. ministro, que as ditas palavras de Nosso Senhor assim devem ser entendidas: 'Tu és Pedro, e sobre esta pedra, i. é, sobre mim, edificarei a minha Igreja', (A República, Edição de 17 de janeiro de 1930, p. 12).

Diante das polêmicas apresentadas pelo defensor do catolicismo, o reverendo Agenor Mafra inicia a sua defesa, construindo a sua refutação e dizendo que "sem muita disciplina, sem arte, sem sciencia, sem muita pesquiza, sem nenhuma reza, maceração e jejum, o haveremos de demonstrar", (MAFRA, 1930, p. 18). Isto é, demonstrar que o seu adversário estava equivocado com relação às interpretações sobre o lugar de Pedro no contexto histórico do cristianismo. Dentro das discórdias de Manso Cordeiro, Pedro foi instituído como uma figura central dos confrontos, reconhecendo-o e aceitando-o como o primeiro papa da história do cristianismo, de viés católico romano.

O que se pode perceber, a partir da análise das fontes, é a intenção de questionar a interpretação - ou a hermenêutica - do escritor oponente, tomando-se como base das discórdias uma figura que fez parte da trajetória do cristianismo, mas do período da igreja na antiguidade. Tomou-se o texto sagrado, neste caso a passagem do Evangelho de Mateus, e buscou-se "provar" que determinada compreensão estava errada em relação à outra interpretação, retirada do mesmo texto, mas tida como correta pelo outro. 
Chega-se, então, a uma proposta de classificar parte do conteúdo destas discórdias, nomeando-as de Polêmicas Comprobatórias. Nesta terceira e última forma de discórdias, observou-se na análise a tentativa em se atestar aquilo que era "a verdade", em oposição aquilo que foi considerado como uma "falsidade". Notou-se, ainda, que tanto os escritores que defenderam o catolicismo, como o fez Antenor Manso Cordeiro, quanto os escritores que defenderam o protestantismo, como Agenor Mafra, procuraram demonstrar que estavam de posse da única verdade possível e absoluta, e que tal verdade poderia ser comprovada, contrariando os argumentos opositores. No conjunto formado pelas sete cartas, observou-se a intenção de se comprovar o pensamento e a crença de um catolicismo hegemônico, que dificilmente pode ser encontrado na trajetória da sociedade brasileira, em contraste com um protestantismo tido como fragmentado por alguns autores católicos, mas representado pelas diversas denominações confessionais.

Algumas expressões e afirmações podem ser pinçadas do conjunto de sete cartas de Antenor Manso Cordeiro, indicando a possível existência de discórdias que se fundamentaram numa postura de absolutismo religioso cristão na década de 1930.

Eis algumas delas:

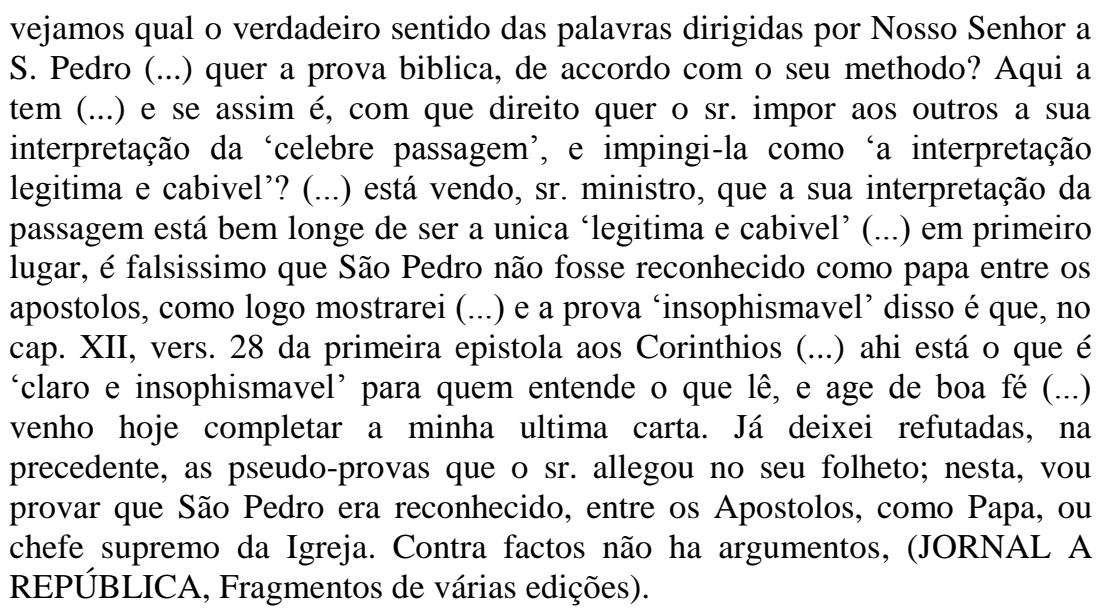

No entanto, se percebe uma intenção semelhante quando se analisa as refutações de Agenor Mafra, buscando convencer o leitor que as verdades religiosas de confissão cristã estavam com os protestantes e não com os católicos romanos, como entendia Manso Cordeiro. 
Pelo lado do protestantismo, o reverendo Agenor Mafra buscou comprovar os seus argumentos, defendendo as suas convicções, apresentadas como verdades absolutas a serem seguidas pelos cristãos:

\begin{abstract}
será possível seccar-se o oceano da graça e do amor de Deus?! Também não há de se provar a veracidade do papismo innovador e antichristão (...) não será importuno nem philaucia transcrevermos para aqui as palavras verdadeiras (...) o haveremos de demonstrar (...) vamos dar uma prova material (...) esclarecimentos que julgamos indispensáveis á bôa comprehensão da verdade dos factos (...) escrevemos o anno passado contra as inverdades do bispo Tadei (...) cite-nos, Exmo. Sr., a Bíblia, ou desista de provar o indemonstrável, i. e., que Pedro foi papa e que os papas são sucessores do apostolo (...) jamais poderão provar que (...) para que todos se convençam (...) é cousa que se pode provar com a maior facilidade (...) ora, facilmente se prova que (...) cremos haver provado, em nossas respostas (...) cremos ainda haver deixado claro, (MAFRA, 1930, fragmentos de seu livro).
\end{abstract}

As discórdias estudadas remetem aos confrontos entre intelectuais cristãos, que polemizaram entre o final do século XIX até a segunda metade do século XX, quando a ideia de se promover e se formalizar o ecumenismo ganhou força de outros adeptos. Assim, pode-se dizer que as discórdias religiosas entre católicos e protestantes foram mais intensas após a Proclamação da República, chegando até a década de 1960, quando católicos e protestantes demonstraram outros interesses, discutindo questões além das polêmicas que os distanciavam. Pode-se dizer também que o ecumenismo percebido na segunda metade do século XX, aproximando católicos e protestantes, indicava avanços e recuos, tanto de protestantes quanto de católicos.

\title{
Considerações
}

Chega-se a algumas conclusões preliminares, a partir das fontes analisadas. $\mathrm{O}$ cristianismo produzido e desenvolvido no contexto social brasileiro não demonstrou sinais de hegemonia, tanto entre católicos quanto entre protestantes. As discórdias religiosas publicadas na imprensa curitibana revelaram as distintas posições assumidas por escritores que defendiam o catolicismo e o protestantismo, dando algumas pistas sobre o pensamento coletivo da igreja católica romana e das igrejas protestantes no Brasil, em defesa de suas convicções e as crenças.

Observou-se, ainda, que os intelectuais católicos percebiam e representavam os protestantes como hereges, afastados da "casa paterna" e rebeldes aos ensinos da única e verdadeira Igreja Cristã, guardiã dos dogmas conservados pelo papa e seus sucessores, 
os legítimos representantes de Pedro. Por outro lado, os autores protestantes percebiam e representavam os católicos como pessoas que se distanciaram dos ensinamentos da Bíblia, tida como a única e suficiente orientação para a vida, desprezando a ideia de uma tradição religiosa.

Foram discórdias religiosas intensas, em busca da proclamação das verdades absolutas, encontradas no catolicismo ou no protestantismo. Foram discórdias empreendidas por intelectuais convictos de suas ideias e certos de que deviam exercer influência sobre a sociedade. Uma sociedade que vivia as incertezas das transformações daquele final do século XIX e parte do século XX. Com as discórdias religiosas, parece que os seus autores desejavam contribuir para o estabelecimento de uma sociedade influenciada pelo pensamento cristão, apontando para um porvir além das vicissitudes de um período em ajustes sócio-políticos.

\section{Referências}

A República. Edição de 17 de janeiro de 1930, p. 12. A República. Edição de 18 de janeiro de 1930, p. 02. A República. Edição de 21 de janeiro de 1930, p. 10. A República. Edição de 24 de janeiro de 1930, p. 12. A República. Edição de 25 de janeiro de 1930, p. 12. KÜNG, Hans. Para que um ethos mundial? Religião e ética em tempos de globalização. São Paulo: Edições Loyola, 2005.

MAFRA, Agenor. O papismo perante a Biblia, a historia e os factos: ligeiras respostas ao bispo de Jacarézinho, sr. Dom Fernando Tadei. Paraná: Editado pela Igreja Presbyteriana de Sengés, 1930.

TADDEI, Fernando. Carta Pastoral A Propaganda protestante e os deveres dos catholicos. Curityba: Officinas Graphicas “A Cruzada”, [192-].

Recebido: 08/10/2012

Received: $10 / 08 / 2012$

Aprovado: 28/11/2012

Approved: 11/28/2012 